\title{
Gastric acid secretion in patients with typhoid fever
}

\author{
S BHALLA, J C VIJ, B S ANAND, A VARGHESE, AND H K CHUTTANI \\ From the Department of Gastroenterology, G B Pant Hospital and Department of Microbiology, \\ Maulana Azad Medical College, New Delhi, India.
}

SUMMARY Gastric secretory studies were carried out in the following groups of patients: group A, 30 Salmonella typhi positive enteric patients, group B, 15 non-enteric fever patients and group C, 20 healthy controls. Patients with typhoid were divided into two subgroups on the basis of the severity of the disease: group $A_{1}(17)$ consisted of uncomplicated cases of enteric fever and group $\mathrm{A}_{2}$ (13) comprised of those who had associated complications. During convalescence both groups of typhoid patients showed significantly lower basal acid output (BAO) and maximal acid output (MAO) levels compared with controls and patients with non-enteric fever. Patients in group $\mathrm{A}_{2}$ had significantly lower MAO levels compared with group $\mathrm{A}_{1}$ but the $\mathrm{BAO}$ levels showed no such difference. In contrast BAO and MAO levels during convalescence in patients with non-enteric fever were similar to those in the control group. After two months, there was a significant increase in both the $\mathrm{BAO}$ and $\mathrm{MAO}$ levels in groups $\mathrm{A}_{1}$ and $\mathrm{A}_{2}$. The levels in group $A_{2}$, however, remained significantly lower compared with group $A_{1}$, controls and patients with non-enteric fever. Histologically, the gastric mucosa did not show any significant abnormality in either group of typhoid patients. The results suggest that depressed gastric secretion is (a) the result of enteric infection and (b) is related to the severity of the disease process.

There is evidence that patients with absent or reduced gastric acid levels are more susceptible to orally transmitted enteric infections. ${ }^{1}$ It has been shown that bacteria introduced into the stomach of healthy subjects fail to reach the small bowel unless the gastric acid is neutralised by means of sodium bicarbonate. ${ }^{2}$

A high prevalence of achlorhydria has been reported in patients with cholera. ${ }^{3}$ It has been observed that gastric juice is bactericidal to Salmonella typhimurium organisms and an increased occurrence of salmonella infection has been found in patients with gastric resection compared with the normal population. ${ }^{5} \mathrm{~A}$ significant reduction of basal and maximal gastric acid concentrations has recently been noted in patients with severe typhoid fever. ${ }^{6}$

Clearly, a close relationship between gastric acid levels and enteric infections is well established, but it is not certain whether the hypochlorhydria seen in such patients is the cause or the result of the enteric infection. In order to examine this further a prospective study of gastric acid concentrations

Address for correspondence: Dr H K Chuttani, G B Pant Hospital, New Delhi 110002. India.

Received for publication 27 June 1984 was carried out in patients with culture positive Salmonella typhi infection and in patients with nonenteric fever.

\section{Methods}

\section{PATIENTS}

Three groups of subjects were included in the study. Group A: 30 male patients with blood culture proven infection with Salmonella typhi, group B: 15 male patients with fever due to infections other than typhoid, and group C: 20 healthy male subjects matched for age and weight with patients in groups A and B and they served as controls (Table 1).

Patients in group A were divided into two subgroups on the basis of the severity of enteric infection; the distinction was made before submitting them to the gastric acid studies.

Group $A_{1}$ (17): Comprised of patients with typhoid fever without any associated complications. Group $A_{2}$ (13): Consisted of those with a more severe infection as indicated by high temperature and one or more complications, such as encephalopathy, meningismus, or peripheral circulatory failure. Patients with intestinal bleeding 
Table 1 Mean $\pm S D$ age, weight, duration of fever and degree of fever in various study groups.

\begin{tabular}{llll}
\hline & $\begin{array}{l}\text { Controls } \\
(n=20)\end{array}$ & $\begin{array}{l}\text { Non-enteric } \\
\text { fever group } \\
(n=15)\end{array}$ & $\begin{array}{l}\text { Typhoid } \\
\text { group } \\
(n=30)\end{array}$ \\
\hline $\begin{array}{l}\text { Age }(\mathrm{y}) \\
\begin{array}{l}\text { Weight }(\mathrm{kg}) \\
\text { Duration of } \\
\text { fever }(\mathrm{d})\end{array}\end{array}$ & $\begin{array}{l}23 \cdot 60 \pm 5 \cdot 84 \\
50 \cdot 05 \pm 8 \cdot 38\end{array}$ & $\begin{array}{l}20 \cdot 46 \pm 5 \cdot 50 \\
47 \cdot 53 \pm 6 \cdot 95\end{array}$ & $\begin{array}{l}18 \cdot 32 \pm 3 \cdot 42 \\
44 \cdot 10 \pm 2 \cdot 60\end{array}$ \\
$\begin{array}{c}\text { Degree of } \\
\text { fever }\left({ }^{\circ} \mathrm{C}\right)\end{array}$ & - & $7 \cdot 80 \pm 3 \cdot 25$ & $8 \cdot 20 \pm 4.05$ \\
\hline
\end{tabular}

or perforation were excluded from the study.

The non-enteric fever group comprised of five patients with malaria (positive for Plasmodium vivax) four with viral fever and six patients with pneumonic consolidation of the lungs. Patients with malaria were treated with chloroquin. Patients with viral fever presented with high temperature, severe malaise and the fever subsided without any specific therapy. On investigation they were negative for any bacterial or protozoal infections. Pneumonic consolidation of lung was diagnosed radiologically. In four patients consolidation was caused by pneumococcal infection, in one by Klebsiella, and one failed to grow any organism. In all patients this was resolved on specific antibiotic therapy (penicillin and/or chloramphanicol).

The mean duration of fever and the degree of body temperature at admission were similar in the two patient groups (Table 1).

Basal and stimulated acid concentrations were measured in patients with enteric fever one week after the temperature had returned to normal and again at the end of two months. Similarly patients with non-enteric fever were assessed one week after the fever had subsided, however, these patients as well as control subjects were investigated only once. Patients in groups A and B were not receiving any drugs at the time of gastric secretory studies.

\section{GASTRIC ACID STUDIES}

After an overnight fast, a nasogastric tube (Levine type) was fixed to the side of the face by means of an adhesive tape and passed with the tip positioned in the most dependent part of stomach by performing water recovery test. ${ }^{7}$ Subjects were asked to lie on the left side and this position was maintained throughout the study. Continuous aspiration of gastric contents with a negative pressure suction pump was carried out and also intermittent manual suction with $50 \mathrm{ml}$ syringe. The overnight gastric residue was aspirated for half an hour and then discarded. To prevent contamination by saliva, cotton pledgets were placed under the tongue and discarded when wet. Basal secretions were collected at intervals of 15 minutes, for one hour, and the volume was measured. At the end of one hour an intramuscular injection of pentagastrin (6 $\mathrm{ug} / \mathrm{kg}^{6}$ body weight) was given. The stimulated secretions were also collected at 15 minute intervals for one hour and the volume was measured. Acid concentrations were determined by titrating $5 \mathrm{ml}$ gastric juice with freshly prepared $\mathrm{N} / 10 \mathrm{NaOH}$ solution, using phenolphthalein as an indicator.

\section{GASTRIC BIOPSY}

Gastric biopsy using Roy Chaudhury capsule ${ }^{8}$ was carried out in typhoid patients during early convalescence on the first or second day after the secretory test. Biopsy specimens were examined in a blind fashion, the examiner therefore being unaware of the clinical status of the patients.

The results were analysed by using the paired or unpaired $t$ test as appropriate.

\section{Results}

BASAL ACID OUTPUT

Basal acid output (BAO) concentrations in groups $A_{1}$ and $A_{2}$ during convalescence were significantly lower than that in the controls and non-enteric fever patients (Table 2). There was, however, no significant difference in the concentrations between groups $A_{1}$ and $A_{2}$. Basal acid output con-

Table 2 Mean $\pm S D$ basal and stimulated acid values in various study groups.

\begin{tabular}{lcccc}
\hline \multirow{2}{*}{$\begin{array}{l}\text { Gastric acid secretion } \\
(\text { mmol/h) }\end{array}$} & Controls $(n=20)$ & $\begin{array}{l}\text { Non-enteric fever patients } \\
(n=15)\end{array}$ & \multicolumn{2}{c}{ Typhoid patients during convalescence } \\
\cline { 4 - 5 } & \multicolumn{1}{l}{$A_{1}$} & $A_{2}$ \\
\hline BAO & $4 \cdot 15 \pm 1 \cdot 41$ & $4 \cdot 08 \pm 0 \cdot 77$ & $2.73 \pm 0 \cdot 94^{*}$ & $2 \cdot 03 \pm 1 \cdot 41 \dagger$ \\
MAO & $18 \cdot 39 \pm 2 \cdot 61$ & $18 \cdot 50 \pm 3 \cdot 60$ & $14.18 \pm 2.11 \dagger$ & $9 \cdot 88 \pm 2 \cdot 58 \dagger$ \\
\hline
\end{tabular}

${ }^{*} \mathrm{p}<0.01+\mathrm{p}<0.001$ (Compared with controls) 
centrations were similar in control subjects and non-enteric fever patients.

PENTAGASTRIN STIMULATED ACID OUTPUT

During convalescence the maximal acid output (MAO) concentrations in group $A_{1}$ and $A_{2}$ were significantly $(p<0.001)$ lower than that in the controls and non-enteric fever patients. Maximal acid output concentrations in group $A_{2}$ were significantly lower than that in group $\mathrm{A}_{1}$ and nonenteric fever group $(p<0 \cdot 001)$. There was no significant difference between controls and nonenteric fever patients.

\section{GASTRIC ACID LEVELS IN TYPHOID PATIENTS}

\section{AFTER TWO MONTHS}

\section{Basal acid output}

There was a significant $(p<0 \cdot 01)$ increase in the BAO concentrations in group $A_{1}$ compared with the convalescent values (Fig. 1) and control levels. In group $A_{2}$, although there was a significant rise in BAO concentrations $(p<0.05)$ over the convalescent levels, the values were still significantly lower than that in controls $(\mathrm{p}<0.01)$ and group $\mathrm{A}_{1}$ $(\mathrm{p}<0 \cdot 01)$.

\section{Pentagastrin stimulated acid output}

Stimulated gastric acid concentrations showed a significant increase $(p<0.001)$ over the initial concentrations in groups $A_{1}$ and $A_{2}$ (Fig. 2). In group $A_{1}$, the MAO concentrations were similar to

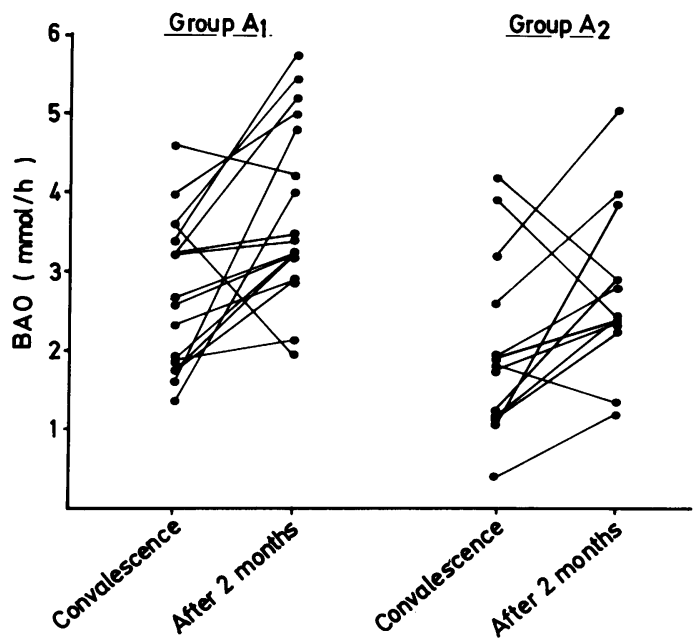

Fig. 1 BAO in patients with enteric fever during convalescence and after two months showing a significant rise in acid concentrations ( $p<0.01$ for group $A_{1}$ and $p<0.05$ for group $A_{2}$ ).

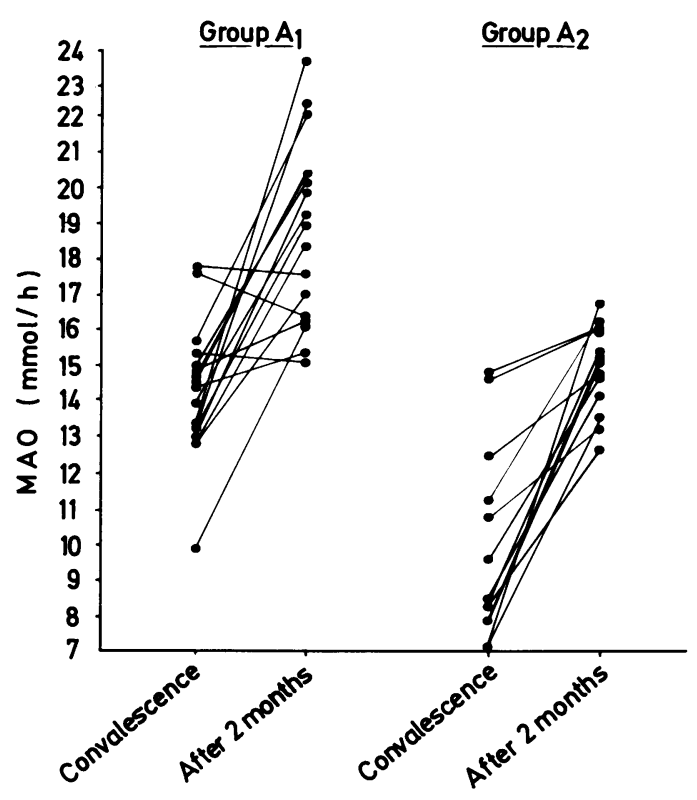

Fig. $2 M A O$ in patients with enteric fever during convalescence and after two months showing a significant rise in acid concentrations ( $p<0.001$ for both groups).

those in control subjects, while in group $\mathrm{A}_{2}$ despite a significant rise the MAO concentrations remained lower compared with the controls $(p<0.01)$ and group $A_{1}(p<0.01)$.

\section{GASTRIC HISTOLOGY}

Gastric biopsy specimens were obtained in 27 of 30 typhoid patients. At histology, seven showed superficial gastritis and the remainder (20 patients) had normal mucosa. No positive correlation was obtained between the severity of typhoid fever and the histological abnormalities; four of the patients showing gastritis belonged to group $A_{1}$ and three to group $\mathbf{A}_{2}$.

\section{Discussion}

Patients with typhoid fever during the early convalescence stage had significantly reduced basal and maximal acid outputs compared with the control group. Maximal acid output values were significantly lower in patients with a more severe form of enteric fever (group $A_{2}$ ) compared with those with a milder disease (group $A_{1}$ ) although no such difference was observed in respect of the basal acid concentrations. It should be emphasised that at the time of the study the patients had 
recovered completely and were not suffering from hypotension, hypovolemia, or electrolyte imbalance, nor were they receiving dry drugs, factors which may influence gastric acid secretion.

At two months there was a significant increase in basal and maximal acid concentrations in both groups of patients with enteric fever compared with their convalescent values. Group $A_{1}$ patients achieved normal acid concentrations, both basal and stimulated, while such values in group $A_{2}$ patients were significantly lower than those in the control group. It should be noted, however, that even group $\mathrm{A}_{2}$ patients had a significant rise in acid output over the convalescent values.

It is therefore apparent that patients with enteric fever have a significant reduction in hydrochloric acid secretion and that this derangement recovers in a short time. Depressed secretion in group' $\mathbf{A}_{2}$ patients at two months may indicate a more severe derangement of gastric functions which simply takes a longer time to recover. Alternatively, group $\mathrm{A}_{2}$ patients may have pre-existing hypochlorhydria which predisposes them to a more severe infection. In view of a significant increase in the gastric acid levels at two months, however, it is more likely that the reduction in acid secretion is the result of typhoid infection rather than a preexisting defect.

Reduction in acid secretion in enteric infection does not seem to be because of the fever itself because no change in gastric acid concentrations, both basal and stimulated, were observed in patients with non-enteric fever who had a similar range of body temperature. Besides, hypochlorhydria has been observed in patients with cholera where fever is rare. ${ }^{3}$ Reduced acid secretion does not seem to be related to any damage to the gastric mucosa as only seven of 27 cases showed superficial gastritis which is not significantly different from that reported in the normal Indian population. ${ }^{9}$ Sack et $a l^{3}$ observed a severe reduction of stimulated gastric acid output during acute cholera which showed a definite improvement when the same patients were subsequently examined. It is postulated that the cholera enterotoxin may be responsible directly or indirectly for the defective acid production, and is presumed that typhoid toxin(s) play a role in suppression of acid secretion. Such a hypothesis, however, remains presumptive and further studies are required to determine the mechanism of the decreased acid secretion in typhoid fever.

\section{References}

1 Gianella RA, Broitman SA, Zamchek N. Influence of gastric acidity on bacterial and parasitic enteric infection. A perspective. Ann Intern Med 1973; 78: 271-6.

2 Dupont HL, Hornick RB, Synder MJ, et al. Immunity in shigellosis $\mathrm{I}$. Response of man to attenuated strains of shigella. J Infect Dis 1972; 125: 5-11.

3 Sack GH, Pierce NF, Hennessey KN, et al. Gastric acidity in cholera and non-cholera diarrhoea. Bull WHO 1972; 47: 31-6.

4 Meynell GG. Some factors affecting resistance of mice to oral infection by Salmonella typhimurium. Proc $R$ Soc Med 1955; 48: 916-8.

5 Waddell WR, Kunz LJ. Association of salmonella enteritis with operations on the stomach. N Engl J Med 1956; 255: 555-9.

6 Gupta PS, Kaul GN, Minotra SK, et al. Pentagastrin stimulated gastric acid secretion in typhoid fever - a preliminary communication. Indian J Med Res 1978; 68: 575-9.

7 Hassan MA, Hobsley M. Position of subject and of nasogastric tube during a gastric secretion study. $\mathrm{Br}$ Med J 1970: 1: 458-60.

8 Roy Choudhury DC, Nicholson GI, Cooke WT. Simple capsule for multiple intestinal biopsy specimens. Lancet 1964; 2: 185-6.

9 Tyagi KP, Mukhopadhyay AK, Aggarwal HK, et al. Gastric mucosal morphology in tropics and influence of spices, tea and smoking. Nutr Metab 1974; 17: 129-35. 